\title{
COMPROMISO Y CREATIVIDAD ARTÍSTICA EN EL REALISMO DE MONTXO ARMENDÁRIZ
}

\author{
José Luis Sánchez Noriega \\ Universidad Complutense de Madrid \\ noriega@ghis.ucm.es
}

\begin{abstract}
Resumen: Reivindicación de la figura del Montxo Armendáriz como autor cinematográfico adscrito a la tradición del realismo comprometido de la cultura española. Analista de conflictos contemporáneos (inmigración, anomia juvenil, drogodependencia, abusos a menores, debate sobre la Memoria Histórica, etc.) su cine se caracteriza por la perspectiva humanista determinada formalmente por textos fílmicos construidos desde el punto de vista subjetivo a través de personajes-narradores.
\end{abstract}

Palabras clave: Cine español, conflictos actuales, punto de vista, realismo.

Abstract: Vindication of the figure of Montxo Armendáriz as a film author attached to the tradition of committed realism of Spanish culture. Analyst of contemporary conflicts (immigration, youthful anomie, drug addiction, child abuse, discussion on the Historical Memory, etc.) his cinema is characterized by the humanistic perspective formally determined by filmic texts constructed from the subjective point of view of character-narrators.

Keywords: Spanish cinema, current conflicts, point of view, realism.

\section{VINDICACIÓN DE UN ARTESANO}

on una obra escasa de cuatro cortos y nueve largometrajes ${ }^{1}$ y un tanto a contracorriente de modas y tendencias innovadoras, el director navarro Montxo Armendáriz (Olleta, 1949) es uno de los cineastas más personales

\footnotetext{
${ }^{1}$ Es autor (guionista y director) de los cortometrajes Paisaje (1980), Ikusmena (1980), Ikuska 11 (1980) y Carboneros de Navarra (1981); y los largos Tasio (1984), 27 horas (1986), Las cartas de Alou (1990), Historias del Kronen (1995), Secretos del corazón (1997), Silencio roto (2001), Escenario móvil (2004), Obaba (2005) y No tengas miedo (2011).

${ }^{2}$ Con ocasión del estreno de Obaba escribimos el siguiente párrafo que constituye un apretado resumen de las motivaciones para estas páginas que tiene el lector en sus manos: "Con una filmografía pausada y pensada, donde escribe, dirige y produce de forma casi artesanal, convirtiendo cada
} 


\section{6}

Compromiso y creatividad artística en el realismo de Montxo Armendáriz

del panorama del cine español, aunque necesitado de mayor conocimiento y reconocimiento ${ }^{2}$.

En efecto, en la estirpe de creadores tan entregados -incluso obsesivos- como Orson Welles o Stanley Kubrick, con filmografías donde todos los títulos poseen interés por un motivo u otro, el director navarro se embarca en cada proyecto cinematográfico con voluntad decidida, dedicación radical al trabajo y pasión por la obra bien hecha, lo que no puede sino ofrecer el resultado de películas extraordinariamente maduradas, filmes en los que cada frase, vestido, objeto, color, encuadre, gesto, mirada, iluminación, duración del plano, ruido de fondo, sombra, nota musical... han sido cuidadosamente pensados y elegidos tras sopesar otras muchas posibilidades. Este estilo de práctica contrasta en un entorno, como el de la cinematografía española, tan dado desde sus mismos orígenes al amateurismo de la producción, la falta de exigencia en los guiones y, en general, a cierta dosis de improvisación en los proyectos.

$\mathrm{Si}$ al lector le parecen exageradas estas apreciaciones ha de tener en cuenta, además, que Montxo Armendáriz posee esa seña de identidad -inequívoca de los creadores auténticos- que es la insobornable independencia artística, el trabajo al margen de oportunismos y una trayectoria tan pausada como firme. Así ha sucedido con su irrupción en el cine comercial con Tasio, toda una propuesta de contemplación alejada del caligrafismo de las adaptaciones literarias al uso y de las comedias urbanas tan frecuentes en la primera mitad de los ochenta; o en películas que, en el momento del estreno, claramente se anticipan al clima social y cultural propicio para ser recibidas y, de algún modo, vienen a ser etiquetadas como políticamente incorrectas, como sucede con el dedo en la llaga de los conflictos de la inmigración irregular (explotación laboral, racismo, infraviviendas, fraudes con los permisos de residencia, exclusión social...) presente en Las cartas de Alou o con el retrato de una generación hedonista que rompe abiertamente con la precedente en Historias del Kronen. Considero que la primera, estrenada en octubre de 1990, anticipa en casi tres lustros la sensibilización social existente sobre las condiciones de vida de los inmigrantes sin papeles; y la segunda, un relato vertiginoso sobre jóvenes nihilistas de la generación $\mathrm{X}$, se adelanta a todo

\footnotetext{
proyecto en la ocasión de su vida, Montxo Armendáriz figura -para quien esto firma- dentro de la media docena de directores más importantes del cine español. Y ello es así al menos por dos razones de peso; en primer lugar porque no tiene una sola película mala en su carrera, lo cual es consecuencia tanto de su valía personal como del cuidado con que aborda cada proyecto (sólo 7 largos de ficción en veinticinco años); y porque tiene un cine coherente donde convergen dos miradas, aparentemente opuestas, pero de enorme necesidad: el compromiso con la realidad social contemporánea (27 horas, Las cartas de Alou) e histórica (Silencio roto) y la indagación poética del pasado y de las raíces que nos han construido, como aparece en su primer largometraje, Tasio y en Secretos del corazón, su mejor película hasta el momento." (Equipo Reseña, Cine para leer 2005, julio-diciembre, Bilbao, Mensajero, 2006, p. 120).
} 
un estilo de cine que, entre otros muchos, desarrolla Michel Winterbottom. La independencia se completa en el aspecto industrial con el apoyo de Puy Oria, con quien comparte la productora Oria Films. En fin, como escribe Ángel Fernández Santos con ocasión de la concesión del Premio Nacional de Cinematografía en 1998: "Armendáriz es un hombre de cine poco frecuentador de escaparates, casi escondido, libre e integral, con tenaz fidelidad a la recia y elegante materia íntima, irónica y lírica, que alimenta sus serenas y apacibles pero radicales, duras pero ágiles como agua, imágenes. Se premia con él la invención de un mundo, pero también el terco, tal vez fatigoso, despliegue de una ejemplaridad profesional y moral (no hay una sin otra) a prueba de chantajes de la canallería ambiental y de caídas en la trampa de la modernez, la facilidad y el oportunismo." (El País, 25-11-1998).

Comprometido con la realidad en los temas que trata y alejado de indagaciones formales en el lenguaje cinematográfico, en cierto modo Montxo Armendáriz es una rara avis dentro de la primera generación de directores de la democracia, constituida por cineastas que empiezan a rodar en los años de la Transición. Frente a un cine desenfadado, con distintos tipos de comedia (Fernando Colomo, Martínez Lázaro, Ventura Pons, Fernando Trueba, José Luis Cuerda) o singularmente provocador (Almodóvar), frente a propuestas de raigambre cinéfila (José Luis Garci) y obras con vocación autoral (Bigas Luna) el cine de Armendáriz parece un tanto descolocado en los años ochenta y entronca con la preocupación realista de los directores del Nuevo Cine Español. Por ello es más justo situarle como hermano mayor de la generación de cineastas que, ya en la década de los noventa, trabajan en un cine comprometido con la realidad social, como es el caso de Icíar Bollaín, Benito Zambrano, Fernando León de Aranoa o Javier Corcuera, según él mismo ha declarado (Armendáriz, 2003) ${ }^{3}$. La singularidad de este director es llamativa si tenemos en cuenta la inusitada madurez del primer largometraje, Tasio, de un cineasta que no ha asistido a ninguna escuela de cine y toda su formación, exclusivamente autodidacta, tiene lugar con los visionados del cineclub pamplonés de su juventud y la realización de cuatro cortometrajes. También resulta sorprendente la fascinación por el musical americano que consume de joven en cines de barrio -en una tarde ve por triplicado Siete novias para siete hermanos- y que para nada presagia su carrera posterior.

\section{OBJETIVOS Y METODOLOGÍA}

\footnotetext{
${ }^{3}$ En este sentido, creo que se pueden firmar las palabras de Carlos Losilla al considerar que "Muy pocos cineastas españoles han sabido crear un espacio de encuentro fructífero entre el cine de autor y el cine popular, entre las preocupaciones personales y las necesidades de un país respecto a su propia representación en la pantalla. Muy pocos han seguido la historia reciente de España con atención y preocupación. Y aún menos han conseguido plasmarla en sus películas de manera indirecta pero también furiosa, sin intermediarios. Pues bien, Montxo Armendáriz es uno de ellos" (en Rodríguez, 2007: 241).
} 


\section{8}

Compromiso y creatividad artística en el realismo de Montxo Armendáriz

Por tanto, el objetivo de este trabajo es una reivindicación de la figura del cineasta Montxo Armendáriz y una aproximación global a su obra cinematográfica ubicándola en el marco del cine español y en la tradición del realismo comprometido de la cultura española.

La metodología de esta aproximación a la autoría cinematográfica de Montxo Armendáriz se basa, en buena medida, en el trabajo de análisis de textos de Jacques Aumont (2004) en el que se construyen las ideas estéticas de cineastas de referencia de la Historia del Cine a partir de textos no publicitarios ni promocionales, esto es, como se especifica en la bibliografía, de ensayos, tratados, transcripciones de cursos, artículos, memorias y diarios, y "entrevistas de interés teórico (lista muy selectiva)" (sic). Ello se tiene en cuenta con el fundamento teórico de la concepción de narración realista aplicable a Armendáriz que se basa en los relatos con narrador homodiegético, propio de un coherente y riguroso punto de vista de un personaje (vid. Infra, punto 3). El concepto narratológico de punto de vista (modo narrativo) ha venido desarrollándose en la teoría del cine a partir de las teorizaciones que en la literatura han llevado a cabo ensayistas como Gérard Genette y Seymour Chatman y ha adquirido una notable complejidad, tanto por las dimensiones visuales (quién ve), cognitiva (quién sabe) o metáfora o epistémica (quién cree), como por su interrelación con la voz narrativa ${ }^{4}$. La cuestión está en que, más allá de la funcionalidad de una estrategia narrativa y, por supuesto, más allá de los énfasis dramáticos de la adopción de un punto de vista visual, ello implica un "ponte en mi lugar" por el que el cineasta, como dice Magny (2001: 17) "no solo sitúa la cámara en el mejor punto de visión, sino que la coloca allí donde transmita al espectador su visión, su punto de vista, esta vez en el sentido físico, ciertamente, pero también, en el sentido psicológico y por tanto, moral, ideológico" (subrayados en el original). Se trata de una narrativa de la subjetividad en cuanto "instancia o nivel específico de la narración donde el relatar es atribuido a un personaje y recibido por nosotros como si estuviéramos en la situación de un personaje" (Branigan, 1984: 73).

En consecuencia, lo que aquí nos interesa subrayar es la dimensión personal, subjetiva, de unos relatos ante los cuales, dada esta perspectiva narrativa, inevitablemente el espectador se solidariza con el personaje narrador en la dimensión psicológica, moral e ideológica, otorgándose así al texto cinematográfico un sesgo que podríamos llamar, al modo baziniano, ontológicamente humanista en cuanto la figura del personaje conductor de la historia está por encima de la historia misma. Este resultado de ponerse en el lugar del personaje es, en buena medida, lo que la teoría psicoanalítica del cine (básicamente desarrollada por Christian Metz y Jean-Louis Baudry) establece como "identificación cinemática secundaria" por la que el espectador se identifica a lo largo de la película con uno o dos personajes

\footnotetext{
${ }^{4}$ Habría que citar los trabajos de David Bordwell, Nick Browne, Edward Branigan, Shlomith Rimmon-Kenan y François Jost. Una síntesis de estos conceptos se encuentra en Sánchez Noriega (2000, cap. 3) y en Sangro (2011, cap. 2 y 3) hay una indagación teórico-práctica con elocuentes análisis de fragmentos de películas..
} 
José Luís Sánchez Noriega

principales de la ficción de manera que a partir de las características psicológicas, el tipo o el rol desempeñado por el personaje se construye la identificación. El compromiso y la solidaridad del cineasta con los personajes no implica necesariamente una proyección de las ideas del cinematurgo; dicho de otro modo: el cine de Armendáriz no se inscribe en las "modulaciones del yo" o las "estrategias del yo" existentes en diarios fílmicos, autobiografías, autorretratos, películas domésticas y obras filmadas en primera persona (Martín Gutiérrez, ed, 2008).

\section{LAS FÁCETAS DEL DIAMANTE DEL REALISMO}

El cine de Montxo Armendáriz es heredero de la tradición realista que atraviesa como uno de los pilares básicos la Historia del Cine desde los documentalistas británicos de los años treinta, el neorrealismo italiano y el free cinema al realismo social europeo de Ken Loach o Robert Guédiguian de los últimos años. Calificar de realista una práctica artística o cultural resulta, a todas luces, insuficiente, por lo que hay que precisar algo más; bien entendido, de entrada, que a estas alturas todo creador es consciente de que, tan pronto como se nombra la realidad, se lleva a cabo una operación de selección, construcción, convención... donde interviene la subjetividad del artista, la complicidad del receptor y la cultura o la ideología del momento histórico en cuestión. O, dicho de otro modo, quien se decanta por el realismo en su concepción de la obra artística no posee una mente privilegiada que le permite aprehender lo real "sub specie aeternitatis" ni se vale de atajo alguno para llegar a las esencias puras de las cosas. Simplemente, utiliza un lenguaje que, con voluntad de comunicación que supere cualquier idiolecto o jerga, presupone una experiencia compartida de la realidad a la que todo remite de forma inmediata. En todo caso, el realismo es como un diamante, con muchas caras y brillos diversos según incida la luz, que puede servir para lucir y deslumbrar por su belleza o para cabeza de una broca en la industria: porque también se cometen crímenes con la coartada de la realidad...(y no hace falta recurrir al Aristóteles del libro VI de la Metafísica para saber que el ser se dice de muchas maneras. Para abundar en el siempre complejo concepto de realismo cinematográfico puede verse Nichols, 1997, cap. 6).

En primer lugar, ese realismo se predica de la propia sustancia del material audiovisual (imágenes y sonidos) que es la película: frente a cualquier forma de fantasmagoría, infografía, artificios visuales y auditivos o recreación de mundos virtuales, los filmes de Armendáriz reclaman un fuerte anclaje con la experiencia de lo real que tiene el espectador. Todo sonido, objeto, frase, vestido o rostro impreso en el fotograma ha de servir para que el espectador rememore en su experiencia algo muy similar o incluso para que lo identifique con algo familiar, sea porque se tiene un conocimiento directo, sea porque se ubica perfectamente en el mundo compartido por el cineasta y el espectador. Este realismo es menos común de lo que parece, pues relatos tenidos por realistas -como todo el cine de género- suelen remitir más a otras películas y a los esquemas expresivos del género que a la realidad propiamente dicha. 


\section{${ }^{190}$ Compromiso y creatividad artística en el realismo de Montxo Armendáriz}

Ese realismo como anclaje de la ficción cinematográfica con la realidad no impide la creación de historias y de personajes que, sin responder a traslaciones automáticas al audiovisual de tipos reales, vienen a ser significativos o representativos de una determinada realidad. Por tanto, se trata de un realismo que, consciente de las mediaciones del propio lenguaje cinematográfico, quiere ser verosímil, es decir, poseer el aspecto de lo verdadero, de la semejanza con lo real que llamamos verdad. Que este concepto pertenezca, también, a la estirpe ética no resulta gratuito.

La realidad lo es todo -hasta los sueños y las fantasías que habitan únicamente en las mentes son reales, aunque se trate de imágenes que no corresponden a realidades físicas- $y$, al mismo tiempo, no es nada, pues en el momento que es nombrada ya queda reducida o configurada según unos parámetros. Por ello hay que precisar la parcela de realidad que es objeto de la cámara de Armendáriz. Digamos que se trata de una realidad humana que, trascendiendo las singularidades, busca la dimensión social e histórica de las experiencias, conflictos, modos de vida, relaciones, anhelos... de las personas. Obsérvese que no decimos "cine social" porque ello sería muy reduccionista, como tampoco decimos "documental", a pesar de la querencia por este formato y de la condición de documento que acaban adquiriendo algunas películas. Se trata de la realidad del ser humano inmerso en el mundo, lo que supone tener en cuenta las dos grandes dimensiones que nos construyen como personas (historia y sociedad) y que confluyen en la historicidad del devenir existencial, cultural y político de cada sujeto, que es inseparable de las relaciones sociales (no menos existenciales, culturales y políticas).

El director es consciente de esta apuesta en una conversación con Lola Mayo: "De una manera o de otra, el cine siempre refleja la realidad del momento, unas veces explícitamente y otras veces por omisión, contando a través de lo que oculta. El cine debe hablar, para mí, de la condición humana. Se habla a veces de cine social o de cine político, pero a mí lo que me interesa sobre todo es la condición humana, es decir, por qué una persona ama, odia, llora y ríe, por qué busca. Porque eso es algo común a todas las personas del mundo: por qué alguien busca la felicidad, o por qué no entendemos la muerte. Estos son temas universales, pero que cada uno vive de una manera personal, y la forma en que transmitimos esas vivencias personales a través del cine o de la literatura es lo que establece una comunicación" (Rodríguez, 2007: 81, subrayado nuestro). El mismo compromiso explica a propósito del proyecto de No tengas miedo: “... seguía recopilando materiales sobre el tema [de los abusos a menores], leyendo libros, hablando con ellas, acumulando anécdotas, hechos, frases, gestos, etcétera, porque tanto dolor, tanta impotencia y tanta lucha no podían quedar en el anonimato, no podían quedar silenciados al igual que quienes los sufrían" (Armendáriz, 2011).

Finalmente, es importante señalar la mirada o la perspectiva ética de este realismo: sin concesiones al espectáculo ni -menos aún- al morbo con o sin coartada, sin dejarse tentar por el entretenimiento o los esquemas de género, 


\section{José Luís Sánchez Noriega}

sin gratificaciones al espectador o explicitudes al público indolente, el cine de Armendáriz refleja la realidad humana, social e histórica desde la convicción del juicio moral implícito en el testimonio. Se trata de observar el mundo con la fuerza de la mirada que, por el mero hecho de mantener los ojos bien abiertos o no volver la cabeza, ya constituye una denuncia o reclama un estilo de vida con los valores supuestos en uno y otro caso. Pero también se trata de captar la autenticidad de lo real a través de la verdad de la mirada de los personajes, ya que la mirada implica conocimiento, interpelación y juicio ético ${ }^{5}$.

No hace falta dejar cerradas las historias con conclusiones o moralejas ni verbalizar en diálogos los principios éticos para hacer un cine comprometido. Este componente ético no tiene nada que ver con un discurso autoritariamente moralista, sino con hacer posible que el espectador se cuestione sus convicciones a partir de la observación en la pantalla de historias y personajes, adquiera un conocimiento de realidades ignoradas o sea solidario con el sufrimiento ajeno. Esta dimensión tiene que ver con la ética del cineasta en cuanto tal, que respeta la intimidad del personaje evitando todo voyerismo, como es muy evidente en una propuesta como No tengas miedo, donde el tema (abusos sexuales a menores) ofrece un tratamiento solidario con el pudor de la víctima, que es al mismo tiempo el personaje narrador.

Estas dos últimas dimensiones son solidarias entre sí -sólo desde una mirada ética es posible hablar de los seres humanos inmersos en el mundo- y vienen a configurar el núcleo de la identidad del cineasta. Por el contrario, la ausencia de esa mirada llevaría a la cosificación de las personas -la ausencia de pudor y la falta de compromiso con los personajes que Armendáriz rechaza con energía- o a la manipulación de la realidad para hacer de ello un espectáculo o un entretenimiento.

En fin, realismo tangible en la materia audiovisual, realismo en la verosimilitud de personajes y situaciones, realismo humanista en cuanto a discurso referido a las mujeres y hombres en su medio social e histórico y realismo ético como mirada comprometida con la realidad son las dimensiones o formas en que puede comprenderse esta breve pero sustanciosa filmografía. Y sólo teniendo como cimiento esta perspectiva alcanzan su verdadero sentido las páginas que vienen a continuación y que son una especie de geografía o estudio del mapa del cine de Armendáriz donde, según queda indicado, hemos optado por dar voz al propio director conscientes de que -aunque no pueda erigirse en juez y parte- es el

\footnotetext{
5"El cine es sobre todo mirada, imagen. Lo que le distingue fundamentalmente de la literatura es que ésta debe describir a los personajes, contarnos cómo son, mientras que en el cine los vemos y, en cierto modo, sus propias miradas nos describen su personalidad. En la mayoría de las ocasiones es la propia expresión de los personajes la que nos transmite lo que están sintiendo. Tanto en cine como en la vida, me creo más lo que me transmite una persona que lo que me dice. Todos podemos engañar con lo que decimos, pero es difícil -salvo que uno sea un gran actor- que seamos capaces de engañar con la mirada y con la expresión. A mí me interesa ese tipo de cine, hecho de miradas y expresiones, que es también el que más me interesó en mi juventud." (Armendáriz, 2005).
} 


\section{2}

Compromiso y creatividad artística en el realismo de Montxo Armendáriz

mejor conocedor de su propio cine.

\section{LA DOCUMENTACIÓN COMO FUENTE DE CREATIVIDAD}

El punto de partida para cualquier proyecto cinematográfico es la cuidadosa recopilación de datos y la inmersión en la realidad objeto de interés y, en principio, susceptible de servir de inspiración para una película. No podía ser de otro modo en quien considera que "siempre me ha costado la invención abstracta de una historia. Considero absolutamente esencial conocer el material humano, los ambientes, el comportamiento de los personajes, porque si no, me siento perdido" (Armendáriz, 1998a: 247). La explicación del director sobre este proceso, realizada a propósito de Tasio y Las cartas de Alou nos ahorra cualquier otra: "Estas dos películas, Tasio y Las cartas de Alou, responden a una motivación común: están basadas en personajes y hechos reales, y por lo tanto, surgen de la preocupación e interés por trasladar a la pantalla historias que reflejen parcelas de la realidad que uno contempla a su alrededor. Sin embargo, esta motivación básica no es suficiente para convertir cualquier suceso o personaje de la realidad en relato cinematográfico: para ello, se necesita que esa realidad o ese personaje reúna los elementos adecuados que permitan construir la estructura narrativa y temática de aquello que se pretende contar. $Y$ esto no siempre es posible, o no se encuentra el punto de vista idóneo para abordar la historia. Truman Capote estuvo seis años paseándose por las llanuras de Kansas buscando la motivación oculta de unos personajes y una sociedad que, finalmente, retrató de forma magistral en A sangre fría. Durante todos estos años recogió datos, anécdotas, contrastó hechos y entrevistó a gente, sin tener la certeza de que detrás de todo ello había una novela. Con igual incertidumbre y similar método de trabajo me planteé la escritura del guión de las dos películas citadas: durante tres meses conviví con emigrantes africanos recogiendo en vídeo sus ilusiones, su marginación y sus precarias e injustas condiciones de vida; a lo largo de un año visité periódicamente a Anastasio Ochoa -el Tasio de la vida real-, grabándole en largas y amistosas conversaciones el relato de su vida. En ambos casos buscaba una motivación específica, determinante, que transcendiese el conjunto de anécdotas y datos que había recogido y les diera un sentido más profundo y universal". (Armendáriz, 1997).

La elección de actores poco conocidos o tipos no profesionales en un laboriosísimo trabajo de confección del reparto se debe a la misma pretensión de conseguir para las películas un realismo documentado. En las antípodas del cultivo del glamour y del recurso al estrellato para poner en valor el producto audiovisual, se opta por películas con protagonistas desconocidos en los cuatro primeros títulos o se combinan actores nuevos con otros consagrados (Secretos del corazón y Obaba). Con la competencia existente en las taquillas y el reconocido peso del reparto en la elección de los espectadores, hay que tener mucha confianza en uno mismo para iniciarse en la profesión con cuatro películas sostenidas por actores nuevos que nunca desaparecen de la pantalla. También hay que tener en cuenta la importancia de los rostros en unos relatos que descansan totalmente 
sobre la credibilidad y fuerza dramática de los personajes.

Al respecto, el director ofrece el siguiente testimonio: "La credibilidad de una historia se sustenta en gran medida en la credibilidad de sus intérpretes. El rostro humano es sin duda el punto de partida de nuestro trabajo y la característica más sobresaliente y diferencial del cine. La fisonomía de los personajes debe corresponderse con la del entorno donde se mueven y, esto te obliga, cuando la película se desarrolla en ambientes determinados, a elegir actores naturales de ese medio, sin experiencia interpretativa. Tenía muy claro que los intérpretes de Las cartas de Alou debían ser los propios emigrantes y, aunque no tuve problemas con la producción en este sentido, había que buscarlos, ensayar con ellos y establecer una dinámica de rodaje diferente, que se adecuase a estas circunstancias. De igual forma, quería que los protagonistas de Tasio fueran rostros nuevos, prácticamente desconocidos: me encontré con varios productores que apuntaban la necesidad de incorporar al actor y a la actriz de moda en aquellos momentos para dar 'consistencia' a la historia. En este caso, además, el lenguaje y su acentuación tenían una importancia fundamental, y los principales intérpretes de la película tuvieron que pasar varias semanas en la zona de Navarra donde rodábamos, practicando con sus habitantes el acento y su peculiar forma de hablar. Todos estos elementos encarecen y ralentizan la producción y no todos los productores están dispuestos a asumir un proyecto de estas características." (ibidem).

Esta documentación y empatía hacia las vivencias de los protagonistas reales de sus historias -en definitiva, la fidelidad a lo real- le lleva a respetar incluso las opiniones de los actores en cuestiones de creatividad de la exclusiva competencia del director, como es la escala y duración de un plano, como cuando los inmigrantes africanos de Las cartas de Alou le permiten que filme la oración musulmana siempre que sea un segmento completo y lo haga en plano general.

De hecho, toda la filmografía del director navarro se puede comprender, también, como una tensión entre el documental y argumental, entre la realidad percibida y la realidad ficcionada, entre el conocimiento y el sentimiento, entre los datos más evidentes y la realidad latente a la que sólo se accede desde la imaginación; quizá porque Armendáriz es de los creadores en los que esa distinción tan convencional ha quedado definitivamente obsoleta. Dos de sus cuatro cortometrajes pertenecen al género documental, todos los estudiosos han subrayado el carácter de documento que poseen ficciones como Tasio y 27 horas y películas argumentales como Silencio roto no dejan de ser un modo de aproximación a la Historia que tiene en La guerrilla de la memoria (Javier Corcuera, 2002) el oportuno complemento estrictamente documental con las entrevistas a los maquis reales. $\mathrm{Y}$ en No tengas miedo hay una secuencia -la de testimonios de personas que han sufrido abusos sexuales en una sesión de terapia- en la que literalmente la ficción se hace documental en cuanto el espectador no sabe literalmente si se trata de actores interpretando un papel o de auténticos protagonistas que hablan ante la cámara. Al final, "Parece que en la obra del cineasta, cualquier relato de 


\section{4}

Compromiso y creatividad artística en el realismo de Montxo Armendáriz

ficción necesita del contrapunto documental a la vez que cualquier película que captura la realidad tal cual requiere de su contraplano con personajes imaginados" como deja sintetizado Quim Casas (Rodríguez, 2007: 56).

\section{UNA NARRATIVA DE INEVITABLE VOZ HUMANA}

Todas las películas del director navarro son relatos contados por un personaje, es decir, poseen un punto de vista personal desde la perspectiva de un personaje. Frente a la habitual narración omnisciente donde un narrador cinemático conoce el pensamiento de los personajes, lo que hacen, su pasado y su futuro, Armendáriz opta por un narrador intradiegético, limitado, que sabe algunas cosas e ignora otras; frente a la omnisciencia como cualidad o posición divina se erige el conocimiento más limitado de la posición humana: "El punto de vista viene dado en función de la historia: por ejemplo, en Tasio y Las cartas de Alou son los personajes quienes cuentan la historia, no el director, y, por tanto, tengo que dar la voz a esos personajes y poner la cámara no donde yo quisiera, sino donde ellos contemplan la realidad o tienen las vivencias. El guión y la planificación tienen que respetar esa mirada, que es la herramienta para reconstruir la realidad y darle sentido, pero sobre todo es una posición ética. Yo le doy la voz a Alou para que él cuente cómo nos ve a nosotros" (Armendáriz, 2007).

Más explícitamente, el cineasta señala la coherencia en todo el proceso, desde la documentación inicial y escritura del guión a la realización y la visión del espectador, presidida por un aliento ético que conlleva decisiones en la enunciación fílmica y que hacen de cada película un cine de voces humanas: "Comencé la escritura del guión después de convivir tres meses con distintos grupos de inmigrantes africanos. Durante ese tiempo, fui descubriendo la realidad en que vivían: ilegalidad, miseria, desprecio, soledad... Y también fui conociendo las motivaciones que les habían impulsado a dejar su tierra para venir hasta aquí: trabajo, supervivencia, dignidad, esperanza, ilusión... Lo primero que debía hacer era decidir la mirada, a través de la cual acercarme a la historia que quería contar y el punto de vista para narrarla. Tenía dos posibilidades: elegir mi propia mirada, mi posicionamiento ante las condiciones de vida -injustas e inhumanasen que vivían los inmigrantes, o dejar que fuese su mirada la que contase esa realidad. En el primer caso, la película se convertía en una denuncia del racismo y de la marginación que sufren los inmigrantes en nuestro país; en el segundo, se trataba de darles la voz a ellos, de vernos a nosotros a través de su mirada. Esta segunda opción ofrecía la posibilidad de mostrar una España vista por los ojos de los inmigrantes y permitía que el espectador conociese esa realidad, que la viese con sus propios ojos — como yo la había visto- y sacase sus propias conclusiones. Bajo esta mirada, el espectador se convierte en observador y juez de lo que se muestra, queda involucrado en la historia y debe valorar la realidad que los inmigrantes ponen ante sus ojos, no la opinión o actitud que el director tiene de esa realidad. Elegir esta opción implicaba varios riesgos, pero era la que más me convencía. Se trataba de darle la vuelta al enunciado del discurso 
fílmico: si podemos mirar a los otros, ¿por qué no vamos a poder ser vistos por los otros?" (Armendáriz, 1998b: 189).

Esta opción tiene trascendencia en la arquitectura del relato, la enunciación cinematográfica y la posición del espectador (dimensión narratológica), en el carácter y modo de expresión artística que adquiere la historia (dimensión estética) $y$, en cuanto todo relato subjetivo inevitablemente está abocado al relato autobiográfico, conlleva asimismo una visión personal y humanista sobre el mundo (dimensión ética). Ya queda indicada más arriba el carácter ontológicamente humanista que adquiere esta filmografía en la particular perspectiva proporcionada por esta opción.

La existencia del narrador-personaje ofrece una dificultad evidente en la escritura del guión y en la puesta en escena, dado que es preciso justificar en todo momento su omnipresencia en el relato y las acciones de otros personajes sólo existen si el narrador las conoce. Mucho más si, como es el caso, se trata de relatos en tiempo continuo ( 27 horas) sin posibilidad de alteración del orden cronológico. Narrar desde la perspectiva de un personaje implica, en primer lugar, construir un personaje con la suficiente entidad como para que descanse sobre él todo el relato y el ritmo no desfallezca; en segundo lugar, supone que el director y el espectador empatizan y, de algún modo, se identifican con el personaje, lo que conlleva participar de su mundo, valores, conductas o relaciones. Que esto no es fácil se percibe en casos de comedias donde la caracterización del personaje-narrador resulta tan escasamente atractiva que se produce un radical desinterés en los espectadores; que es problemático se ve en Historias del Kronen, donde un tipo como Carlos no sólo impide la identificación de la mayoría del público, sino que llega a producir el rechazo frontal.

El director que opta por un relato de focalización interna desde un personaje se decanta por un cine complejo y adulto, un cine nada fácil, tanto por las dificultades señaladas como por la distancia y la empatía que el director en cuanto narrador cinemático mantiene con el narrador-personaje. Esta última relación supone, de hecho, una apuesta del cineasta por un cine humanista, pues, como queda apuntado, no otra cosa han de ser unos relatos cinematográficos narrados desde la dimensión de los humanos.

Por tanto, además de la dimensión narratológica la opción por un narrador-personaje posee un ethos humanista en cuanto la posición desde la que se contempla la realidad es la de una persona $y$, simultáneamente, en cuanto la realidad reflejada tiene como materia prima ese ser personal. Al margen de otras muchas consideraciones, el cine de Armendáriz son las historias de Tasio (Tasio), Jon (27 horas), Alou (Las cartas de Alou), Carlos (Historias del Kronen), Javi (Secretos del corazón), Lucía (Silencio roto), Lourdes (Obaba) y Silvia (No tengas miedo); y esas películas son fragmentos más o menos completos de las vidas de esos personajes. Pero hay que tener en cuenta que, por debajo del narrador personaje, sustentándolo, está el director en cuanto autor implícito de los relatos que va dejando sus huellas o haciendo guiños al espectador, lo 


\section{6}

Compromiso y creatividad artística en el realismo de Montxo Armendáriz

que aporta un matiz decisivo a la perspectiva del narrador personal. Así, aunque aceptemos el artefacto narrativo -al margen de posibles licencias poéticas-, el relato de Secretos del corazón posee componentes que no responden a la mente infantil que presuntamente lo ha elaborado, pues, como señala Roberto Cueto, el director "en vez de mostrar el mundo desde los ojos de un niño, opta por enseñar - a veces con notable didactismo- el proceso con que un niño se apodera del mundo iluminando las zonas de sombra que lo rodean, como si se tratara de un espeleólogo con un haz de luz en su casco. Su estilo narrativo nunca adopta la manera de la primera persona, sino que confía en una especie de estilo indirecto libre que parte de lo objetivo para sumergirse en lo subjetivo y regresar de nuevo a lo objetivo con todas las inflexiones y preguntas que impone esa mirada desconcertada y maravillada a un tiempo." (Rodríguez, 2007: 150).

En esta narrativa comprometida con la voz de los personajes, éstos, no por azar, representan situaciones, encarnan condiciones o valores y vienen a situarse en el centro de la cosmovisión del director, de su ser ciudadano comprometido con el mundo y la sociedad contemporáneos. Son tipos humanos muy diversos: un campesino que vive fabricando carbón vegetal y no se doblega ante nadie, un joven de clase media toxicómano y desnortado, un emigrante subsahariano que lucha por sobrevivir, el niño provinciano en trance de descubrir el mundo de los adultos, una joven en el volcán de la cruel posguerra, una víctima de la pederastia o una estudiante en busca de su identidad a través de otros. El director $\mathrm{y}$ el espectador somos todos y ninguno de estos personajes: lo primero, en cuanto hay algo en estas vidas e historias con lo que nos podemos identificar, aunque sólo sea por la condición humana que compartimos; lo segundo porque es imposible, por definición, que reunamos las cualidades y condiciones contradictorias de personajes tan variopintos. Probablemente nos identifiquemos con episodios del niño de Secretos del corazón, aunque nunca nos mintieran sobre nuestro padre, nos sintamos solidarios del sufrimiento de Lucía, Silvia y de Alou o admiremos la libertad de Tasio. Pero resulta más problemático sentirse cercano a Jon o empatizar con Carlos.

En este último caso, en el que se puede producir un desencuentro emocional y cognitivo con el personaje debido a la repugnancia moral que nos ocasiona su conducta, el director arriesga mucho con un cine más desnudo, desprovisto de gratificaciones o complicidades con el espectador, pero, al mismo tiempo, más coherente y comprometido con la citada mirada ética, puesto que no se ha hecho una selección cómoda de la realidad, sino que se aceptan los aspectos menos agradables y hasta los callejones oscuros en los que también habita lo irremediablemente humano. Porque la opción por un narrador intradiegético es, al final, una opción que responde a la perspectiva ética y al realismo humanista indicados más arriba. El director considera que la historia no le era simpática, pero "me interesaba conocer y plantear una reflexión sobre jóvenes que se juegan la vida sin ninguna ética y que el día de mañana van a ser arquitectos, médicos o ingenieros y van a mantener la sociedad. Te enfrentas a un personaje que no te gusta y, a través de otros personajes, cuentas algo distinto y por eso cambio el 
personaje del padre o añado diálogos respecto a la novela con el fin de distanciarme del protagonista" (Armendáriz, 2007).

No obstante, en Historias del Kronen se altera el punto de vista en el tramo final con la filmación de la cámara de vídeo -que es un narrador no personalcon lo que se proporciona al relato un distanciamiento respecto al personaje de Carlos. Con ocasión del estreno explica este compromiso con el punto de vista de los personajes: "Me interesaba narrarlo [el proceso interior de autodestrucción] desde el punto de vista de los personajes, como si la cámara fuera uno de ellos, capaz de ver esa realidad y no quedar perdidos en el entorno de bares y calles" (Dirigido por, $\mathrm{n}^{\circ} 234$, abril 1995).

En su conjunto, esta narrativa del yo plasma en la enunciación la apuesta solidaria del narrador cinemático por la suerte de personajes concretos $\mathrm{y}$, de esa manera, el punto de vista cognitivo del relato es, también, una posición moral. Quiero decir que Tasio no es una historia 'sobre' Tasio, sino la historia 'de' Tasio, y lo mismo puede decirse de todos los personajes mencionados más arriba, pues el guionista-director renuncia a su voz para que el personaje cuente su propia historia. Además, esta opción tiene una función añadida: conseguir un nuevo relato al hablar de temas conocidos desde un punto de vista nuevo. Es lo que sucede de forma muy clara en 27 horas, donde se evita el miserabilismo y el paternalismo habituales al hablar de los efectos de la droga en los jóvenes, y en Silencio roto, donde la lucha guerrillera de los cuarenta -ya contada en Los días del pasado (Mario Camus, 1977), El corazón del bosque (Manuel Gutiérrez Aragón, 1978), Luna de lobos (Julio Sánchez Valdés, 1987) o Huidos (Sancho Gracia, 1992)- es vista desde distintas mujeres: Lucía como joven enamorada, Teresa en inestable equilibrio, Lola y Rosario que tienen a sus seres queridos en el monte o Sole, la mujer del guardia civil, también víctima de la situación. De hecho, el guión inicial estaba escrito desde la perspectiva de los maquis y, en la tercera versión del guión, se cambia el punto de vista: "Un día empecé a trabajar desde otro posicionamiento, porque a esas alturas ya había descubierto que si contaba la historia desde el punto de vista de los guerrilleros quedaban muchas cosas fuera. Entonces comprendí que era mucho mejor adoptar la mirada de las mujeres, de las que se quedaban en el pueblo." (Conquero, 2002, 11).

\section{LA VOLUNTAD DE HACER CINE Y NO PELÍCULAS}

El uso específico del lenguaje cinematográfico o el estilo del cineasta viene siendo definido como clásico; en la medida en que renuncia al exhibicionismo de la puesta en escena, el barroquismo visual, la escritura con la cámara o el montaje efectista y, por el contrario, busca el realismo y el naturalismo en el mundo construido para el rodaje, confía en las emociones derivadas de las miradas, evita que se note la presencia de la cámara o se atiene a la lógica narrativa en el montaje... ciertamente este cine es heredero del clasicismo de cuantos crearon una expresión fílmica con voluntad de perdurar en el tiempo. Porque clásico 


\section{8} Compromiso y creatividad artística en el realismo de Montxo Armendáriz

es aquí sinónimo de intemporal y no de fórmula anquilosada o de opuesto a la vanguardia.

De hecho, el clasicismo de este estilo tiene mucho más que ver con la desnudez preñada de poesía del relato cinematográfico de Robert Bresson o con las emociones fruto de una trabajosa simplicidad de los filmes neorrealistas que con la transparencia narrativa exigida por Hollywood. Este estilo no está exento de voluntad de compromiso, sólo que, a diferencia de obras con mensajes explícitos y aun manifiestamente retóricas en sus explicitudes, prefiere confiar en la inteligencia del espectador: "Lo que más me interesa al hacer una película es contar una historia, narrar unos hechos y contemplar cómo los personajes van reaccionando ante los acontecimientos que les suceden. Si después estos hechos, o la manera en que están reflejados, producen una reflexión en el espectador, o éste saca de ellos una idea de injusticia social, o la necesidad de una denuncia, mucho mejor. Lo que no creo es que la cámara deba intervenir por la vía de añadir juicios de valor o de imponer desde fuera un determinado subrayado." (Armendáriz, 1990).

Deliberadamente, Armendáriz renuncia a la dramaturgia fuerte, a la intensificación de las situaciones de crisis o conflicto, que suele ser uno de los recursos habituales para la gratificación del espectador; en su lugar prefiere la minuciosa reconstrucción de detalles de la cotidianeidad que pueden ser más significativos para transmitir la interioridad de los personajes: "Creo que los momentos dramáticamente fuertes o explícitos son en sí tan evidentes que, muchas veces, tergiversan la estructura dramática de aquello que estás contando. En lo cotidiano ocurren grandes tragedias y las grandes alegrías humanas que todos tenemos y eso muchas veces no se exterioriza. Ésos son los momentos que, aunque no se manifiesten, marcan la vida de cada uno y son los elementos que a mí me gusta incorporar a las historias" (Armendáriz, 1998a: 249)6 .

Esa desdramatización también tiene lugar con la cuidada distancia de la cámara, distancia que viene motivada, a su vez, por el mencionado punto de vista personal de los relatos; es decir, que la cámara carece del don de la ubicuidad propio del enunciador ausente para adoptar una más humilde posición desde el lugar -visual, pero sobre todo cognitivo y ético- del personaje. Como nos hace ver Javier Maqua a propósito de Historias del Kronen: "Lo propio de la mirada

\footnotetext{
6"Como diagnostica Carlos F. Heredero "Sus historias no pretenden extraer conclusiones morales, no tratan de articular un conflicto dramático ni están construidas en función de un clímax liberador $y$, en consecuencia, los incidentes que las componen no traban dramáticamente los relatos al modo tradicional. Su transcurso no requiere una acción trepidante, no recurre a sucesos espectaculares ni cuenta una intriga capaz de generar grandes emociones, porque Armendáriz piensa que los momentos explícitos pueden tergiversar o desnaturalizar la estructura narrativa de las historias.

El paciente trabajo de depuración al que Armendáriz somete esa estructura, ajena siempre a toda instrumentación de carácter psicologista, permite que se desprendan de su transcurso -con suavidad, pero con precisión- múltiples matices internos que, de una forma casi inapreciable, van enriqueciendo la médula de la historia y van creando un sentido interior sin necesidad de complicar los relatos." (en Angulo y otros, 1998: 135).
} 
antropológica es medir las distancias. Si la mirada es demasiado cercana, obtendremos un panfleto, un abigarramiento sentimental, tal vez justo, eficaz incluso, pero incompleto, con lagunas. Si la mirada se aleja en exceso, se diviniza, se ensoberbece y apenas logramos distinguir lo que encuadra, como no sean los propios ojos del que mira. A Montxo siempre le ha preocupado encontrar la distancia justa. Es un obseso del punto de vista." (El Mundo, 31-3-1995).

En el mismo sentido, son significativas las elipsis visuales, auditivas o completas, como se aprecia en el accidente del niño o las torturas de la Guardia Civil en Tasio, las dosis de heroína o la muerte de Maite en 27 horas, la violencia de género en Secretos del corazón, los abusos de No tengas miedo y en los momentos de relaciones sexuales en Las cartas de Alou y el resto de sus filmes, con excepción de Historias del Kronen, donde precisamente el sexo rápido es un rasgo definitorio de los personajes. Las omisiones totales o parciales de los diálogos suelen venir acompañadas por juegos de miradas que sustituyen a las palabras, cumplen la misma función narrativa, añaden poesía al relato y reclaman un espectador activo. Rechaza un cine donde todo aparezca demasiado explícito y cree que viene por influencia de series de televisión donde las cosas se repiten varias veces, todo se da muy masticado y el espectador no tiene opción a elaborar sus propias conjeturas. Considera que ese cine es aburrido, no le interesa nada: su opción es por un cine en el que "el espectador participa y saca sus conclusiones de lo que no se dice, porque en la vida también aprendemos de lo que no nos dicen o cuando nos dicen lo contrario de lo que piensan" (Armendáriz, 2007).

Con ocasión del estreno de Secretos del corazón explica en la prensa esta opción por la distancia y el respeto hacia los personajes: "Los sentimientos están vistos desde el punto de vista de un niño porque ése es el punto de vista que a mí me permite elegir una forma de contar las cosas poco explícita, incluso pudorosa, que me permite obviar muchas cosas e incluir otras. Porque hoy, cuando cualquiera sale en la televisión llorando y diciendo a quién quiere y a quién odia, no está mal reivindicar un poco de pudor y contención a la hora de expresar los sentimientos. Con esta película quería ver si se podía seguir emocionado con una mirada o con un gesto, con esas cosas que se están perdiendo" (El País, 18-3-1997).

La construcción dramática de los títulos de esta filmografía tiende al relato circular, a una clausura que remita al comienzo y, de esa manera, otorgue la sensación de una historia completa. No se trata de un regreso al punto de partida -repetición del mismo ciclo o nueva edición del 'mito del eterno retorno'sino de la convergencia entre el principio y el final con el propósito de 'cerrar' la historia, de presentar un discurso trabado; o, si se quiere, de acompañar a los personajes a lo largo de un viaje completo cuyo final está en el punto de inicio. De este modo, se soslaya el recurrente final feliz o el convencional desenlace que resuelve todos los conflictos planteados en beneficio de una clausura que privilegia el conocimiento o la comunicación de unas ideas en detrimento de los mecanismos de la dramaturgia. Como explicita el director "Decía Aristóteles que 


\section{${ }^{200}$ Compromiso y creatividad artística en el realismo de Montxo Armendáriz}

siempre representamos la misma historia y que lo único que varía es el decorado. Creo que en nuestras vidas uno parte de una situación y después vuelve a encontrarse en otra similar, aunque nunca sea la misma. En las tres películas [del comienzo de su carrera] se vuelve a una situación igual, pero después de haber recorrido un viaje donde se han aprendido cosas, donde ocurren hechos y donde se encuentran con el amor, con la muerte... Es una estructura que me gusta desde siempre, tanto en la literatura como en el cine porque, para mí, es una manera de redondear las historias" (Armendáriz, 1998a: 255).

Entre el inicio y la conclusión -marcados por una acción, gesto, lugar, diálogo, etc. que los une para componer un ciclo completo- los personajes viven una experiencia transformadora o sobre ellos se ha contado un episodio con valor para condensar sus vidas. Con la despedida de la hija de Tasio, que vuelve a estar solo, concluye todo un arco temporal que se remonta a la infancia: así lo indica el lugar (la carbonaera) presente en el inicio y cierre del relato. El reloj que marca la primera y la última de las 27 horas cierra por ambos extremos un relato que, a pesar de la brevedad, contiene todo el mundo actual de Jon y, con la muerte de Maite, es un momento de crisis transformadora de ese joven. La llegada de Lucía en autobús al pueblo de Silencio roto y su marcha ulterior marcan físicamente su entrada y salida en el territorio habitado por las personas y los conflictos que van a alterar su vida y cambiar su perspectiva sociopolítica. La patera que, al principio y al final de Las cartas de Alou, se adentra en el estrecho para llegar a la península ibérica no sólo testimonia con su repetición el tesón del inmigrante y la inutilidad de las expulsiones, sino los límites de una peripecia donde aparecen descritos los problemas de los trabajadores de países pobres que llegan al primer mundo.

Este estilo cinematográfico, renuente a fórmulas barrocas y experimentaciones, asume, no obstante, recursos y procedimientos expresivos divulgados por la Modernidad de los años sesenta, como es el 'cine en el cine'. Ya en el cortometraje La danza de lo gracioso, con un payaso dirigiéndose a la cámara, se reflexiona sobre la posibilidad y el engaño de la plasmación de una realidad, sobre cómo el dispositivo cinematográfico en cuanto sistema construye realmente una representación. Según queda dicho, en Historias del Kronen, el punto de vista intradiegético se ve alterado en el último tramo de la película con el relato impersonal y testimonial de la máquina-vídeo, funcional como 'espejo' en el que los personajes se miran y contemplan las barbaridades cometidas. Por último, en Obaba el hilo conductor de las tres historias es una estudiante de cine que graba con su cámara y se sumerge en el microcosmos de Obaba para desentrañar los

\footnotetext{
${ }^{7}$ Como observa atinadamente Qim Casas, esta película comienza con el personaje narrador intradiegético de Lourdes que "se filma a sí misma mientras habla con un interlocutor inexistente en el relato, que es el propio espectador. Armendáriz abre poco a poco su encuadre, de modo que terminamos viendo en el plano a Lourdes, o el reflejo de su rostro sereno que -como un espejo- nos devuelve la pantalla de la cámara de vídeo, y también en objetivo de esa misma cámara que la ha grabado o la está grabando: el relato en primera persona, el documento subjetivo que da paso a una ficción sin ánimo de objetividad. Lourdes realiza un filme-reportaje sobre un mundo que desconoce por completo" (Rodríguez, 2007: 51).
} 
misterios que, al fin y al cabo, sirven para indagar en el suyo propio․

Este estilo exige un espectador atento, un público activo, dispuesto no sólo a vibrar con las emociones puestas en escena, sino también a conocer mundos próximos y a penetrar en el misterio de cada uno de los tipos humanos que desfilan por la pantalla: "Me interesa que al espectador no se le dé todo ya, digerido, y que éste se construya su propia idea sobre los personajes a partir de los datos que se le proporcionan. Por eso no hace falta insistir en lo obvio, y es mucho mejor potenciar el grado de participación del público en el film" (Armendáriz, 1990).

En uno de los textos más completos sobre su concepción del cine, el director subraya la importancia de la mirada y el punto de vista, dimensiones complementarias bajo las que subyace la actitud ética del cineasta, y la constatación de que "hoy en día nos encontramos con que se pueden ver muchas películas pero poco cine"; a continuación explica el tipo de director que reivindica: "hay dos clases de cineastas: los que utilizan la cámara como un simple objeto técnico de reproducción y los que la utilizan para crear. Son estos últimos los que me interesan, porque -aunque sean minoría - tienen una mirada propia, diferente, del mundo en que vivimos, y son quienes a través de sus imágenes nos recuerdan que el cine tiene un significado que va más allá de su propio consumo. Sería imposible citar a todos, pero nombres como Hal Hartley, Theo Angelopoulos, Nanni Moretti, Lars von Trier, Ken Loach, Bertrand Tavernier, Arturo Ripstein, Woody Allen... sirven para constatar la presencia de miradas con voz propia, que prevalece sobre la mediocridad del cine que llena nuestras pantallas. Podremos identificarnos, o no, con sus películas, podrán ser certeras o fallidas, irritarnos o complacernos, pero tanto si sólo tratan de divertirnos, como si cuestionan la sociedad en que vivimos, tienen una clara voluntad de construir un discurso fílmico con unas señas de identidad propias. Dentro de nuestra cinematografía $-y$ sin entrar en apreciaciones pormenorizadas de sus trabajos-, podemos reconocer la mirada de cineastas como José Luis Borau, Pedro Almodóvar, Víctor Erice, Ventura Pons, Fernando Trueba... o los todavía recientes Fernando León, Alejandro Amenábar, Julio Medem, Isabel Coixet. . . sin olvidar a quienes desde hace tiempo no trabajan o se ven relegados de los circuitos comerciales de exhibición: Paulino Viota, Iván Zulueta, José Luis Guerín, Basilio Martín Patino... (Armendáriz, 1998b: 188-189).

\section{LA FIDELIDAD A LO REAL: ESPACIOS SOCIALES E HISTÓRICOS}

Los espacios humanos en que transcurren las historias de este cine poseen una caracterización precisa que los ubica en un lugar y en un tiempo reconocibles, marcadamente históricos, y que no son otros sino aquellos conocidos por el director. La concreción de estos espacios no supone ninguna limitación localista o provinciana, pues resulta proverbial el valor universal de los relatos.

Pasado y presente se combinan en una dialéctica precisa y variada, en relación directa con el mundo rural y el urbano. En ocasiones se trata de un presente tan deshistorizado, provisional y efímero, tan concreto y reducido -como en 27 horas 


\section{${ }^{202}$ Compromiso y creatividad artística en el realismo de Montxo Armendáriz}

y en Historias del Kronen- que precisamente la dislocación temporal apreciada es reflejo sintomático de la vorágine existencial que experimentan los jóvenes de esas historias. En esos dos títulos se hace un tajo en el devenir vital de los personajes para capturar una instantánea, un momento aislado temporalmente, con lo que queda subrayado el presentismo como 'enfermedad social' de los tipos humanos. En el polo opuesto, el relato biográfico de Tasio o la evocación de la infancia de Javi (Secretos del corazón) se extienden en el tiempo, con voluntad de crónica histórica, dentro de un pasado ajeno al espectador, aunque cercano al autor implícito; en efecto, estas dos películas hablan de un mundo y un estilo de vida en pueblos del norte en trance de desaparición hacia los años sesenta del siglo XX, en la juventud del director. La hija de Tasio que deja el pueblo certifica el final de ese modo de vida, lo mismo que la relación sentimental de María (la tía de Javi interpretada por Charo López) subraya un cambio de mentalidad al mostrar un comportamiento en trance de pasar de la condena a la aceptación social. En estos dos títulos se percibe un homenaje a ese pasado de la vida rural con valores firmes (Tasio, el abuelo de Javi), pero no se trata de una nostalgia reaccionaria que entone el consabido "cualquier tiempo pasado fue mejor" o que oponga el presente urbano y desencantado al pasado rural y puro. Más bien es fruto de la expresión libre de la memoria personal del cineasta, sensible hacia ese mundo, probablemente tanto por los recuerdos afectivos de su infancia como por el aprecio de los valores de ese medio.

Más decantado hacia la recuperación de la memoria histórica, Silencio roto vertebra en tres momentos la evolución de la lucha guerrillera antifranquista de los años cuarenta. Aunque no haya un recuerdo directo, el director posee el conocimiento, a través de numerosos testimonios, como para reconstruir la época; y participa de la sensibilidad política que considera necesario recuperar la memoria histórica de la derrota, no en vano Montxo Armendáriz es productor del ya citado documental de entrevistas a maquis La guerrilla de la memoria. En la presentación de su largometraje explica su pretensión "El guión de Silencio roto es el resultado de largas conversaciones con personas que participaron en los acontecimientos que se narran y de la investigación y lectura de los estudios publicados sobre la guerrilla antifranquista (maquis). Aunque la construcción de personajes y su evolución dramática responden a las necesidades de una estructura narrativa y temática que dé sentido al relato y, por lo tanto, pertenecen a la invención del autor, están inspirados en comportamientos y actitudes reales, de la misma forma que se ha respetado la cronología y acontecimientos más significativos del movimiento guerrillero con el fin de que a través de la peripecia humana de sus personajes se refleje el contexto social y político de la época" (Armendáriz, 2001).

Frente al conjunto del cine español donde la vida rural y los pueblos aparecen siempre como excepción al hegemónico entorno urbano -y, muy frecuentemente, caracterizados por el exotismo, el folclorismo o con rasgos de mistificación paradisíaca y a veces hasta ridiculizados- en el cine de Armendáriz el pueblo y la vida provinciana es el espacio principal en todas las películas, salvo en 27 horas y en Historias del Kronen. Un espacio rural muy diverso, concebido como habitáculo 
natural de los personajes, que abarca los pueblos pequeños rodeados de bosques del norte (Tasio, Silencio roto, Obaba) o el mundo rural herido por la emigración del oeste español (Escenario móvil); en Las cartas de Alou y Secretos del corazón se alternan los pueblos de distinto tamaño y los barrios de las ciudades pequeñas. Son lugares donde la gente se conoce, se establecen relaciones duraderas -no siempre satisfactorias: ahí está la rivalidad de años de los personajes de Tasio, Obaba y Silencio roto-, los niños crecen con los ritos sociales, la familia es un asidero que otorga raíces y donde es posible una relación directa y fecunda con la naturaleza. El monte o bosque es uno de los espacios más cartografiados, con diversidad de tratamientos, desde lugar de aprovechamiento económico o garantía de subsistencia (Tasio) y amenaza por catástrofe ecológica (Escenario móvil) a espacio de resistencia (Silencio roto) o entorno mítico de los pueblos (Secretos del corazón, Obaba). En todo caso, espacios con dimensiones humanas, que contrastan fuertemente con el vértigo urbano en que están sumergidos los jóvenes de aquellos dos títulos; o la dualidad presente en No tengas miedo, donde la ciudad provinciana puede ser tan acogedora como hostil.

El presente sólo encuentra una visión más optimista en el medio rural (Escenario móvil) pues, como queda dicho, los filmes urbanos vienen a ser, también, un diagnóstico pesimista sobre la sociedad actual y el citado presentismo propio de una ciudad que, según describe Beatriz Martínez, "se muestra como un ente inhóspito e inseguro, incapaz de satisfacer las necesidades de las gentes que lo pueblan. Por eso, las narraciones se centran en temas como el desarraigo emocional, la ausencia de horizontes vitales y el refugio en las drogas como medio de escapar de un entorno hostil en el que se sienten atrapados" (en Rodríguez, 2007, 247).

Estos espacios adquieren el espesor de lo real gracias a la verosimilitud proporcionada por la ambientación, la fotografía y, sobre todo, por tres rasgos constantes en este cine. El primero es el cuidado de la prosodia y el vocabulario que han de tener los actores para componer sus personajes; no se emplea el castellano estándar sino que es muy evidente el acento del lugar (Tasio, Silencio roto) o la limitada competencia lingüística (Las cartas de Alou); la autenticidad que el director busca en rostros poco vistos o fotografiados se extiende a la forma de hablar, que ha de remitir a personas reales. Un segundo elemento son las canciones y la música tradicional que aparecen en las películas como un componente propio de la cultura de esos espacios, pues son los personajes quienes cantan o interpretan la música y no procede de una radio o de fuera de la diégesis. Además de las piezas de música clásica interpretadas por Silvia (No tengas miedo) con el violonchelo, las canciones tradicionales entonadas por los personajes con ocasión de fiestas familiares o patronales (Tasio, Secretos del corazón) y religiosas (Obaba), de un momento celebrativo (Silencio roto) o por los grupos de cultura regional (Escenario móvil) subrayan la ubicación de esos personajes en una cultura arraigada en un lugar y en un tiempo. Por último, el realismo socio-histórico de estos relatos se consigue también con juegos, bailes, rituales y tradiciones. La Semana Santa, el Judas quemado, el teatro infantil, los 


\section{4}

Compromiso y creatividad artística en el realismo de Montxo Armendáriz

bailes, el paso del río, la telaraña, el brindis... de Secretos del corazón vienen a ejemplificar un tipo de cine donde se emplean recursos para plasmar la crisis de crecimiento de los personajes o la importancia de las tradiciones que marcan el paso del tiempo o las raíces. Resulta llamativa la reiteración de los juegos -la pelota vasca (Tasio), el futbolín (27 horas), las damas (Las cartas de Alou), los billares (Historias del Kronen), las cartas (Silencio roto) o las máquinas tragaperras (No tengas miedo)- siempre con una función específica dentro de los relatos, habitualmente como duelo o prueba de fuerza entre los personajes. Como también son reiterativos los bailes.

También sucede que los espacios juegan un papel eminentemente narrativo y podíamos analizar en cada una de las películas la interrelación entre las localizaciones y los sucesos narrados, como hace Violeta Kovacsics con 27 horas, "un filme que podría describirse a través de los espacios que habita: el itinerario sin rumbo del protagonista se transcribe en las calles de la ciudad, la muerte por sobredosis sobreviene en una pequeña isla y las dificultosas relaciones paterno-filiales se describen mediante los espacios cerrados de una casa o del negocio familiar. Cada rincón tiene su determinación en la historia, no es un mero fondo sobre el que transcurre la trama. Paisaje y narración se funden en uno" (Rodríguez, 2007: 126).

La fidelidad a lo real es coherente con una actitud de compromiso que Montxo Armendáriz ha demostrado tanto en su cine como en distintas actividades profesionales y sociales, y que viene a plasmar su concepción del cine. Merece la pena este párrafo pronunciado en una reunión de directores europeos en Salamanca con motivo de la capitalidad cultural de la ciudad castellana: "Nadie niega hoy día la importancia del medio cinematográfico, como vehículo de expresión y comunicación. Éste es un hecho innegable, porque el cine, incluso el mal cine, nos habla de una época concreta y de un país concreto, y es un fiel reflejo de la cultura de un pueblo, o de sus carencias culturales. Rossellini lo explicaba con estas palabras: "En cualquier cultura y en cualquier civilización, el arte ha tenido siempre un papel importante: el de dar el significado del periodo histórico en el que se vivía. El cine debe asumir ese papel, más allá de toda preocupación didáctica: debe recrear y analizar la realidad cotidiana, para organizarla nuevamente y mostrar su sentido profundo". Éste es el cine que yo amo, y éste es mi entendimiento del cine." (Armendáriz, 2003).

Más adelante explicita que "... solamente el conocimiento de la realidad puede generar un cambio de esa realidad. $Y$ el cine puede y debe contribuir a ese conocimiento, a ese cambio, a través de la mirada con que el cineasta se acerca a esa realidad. Porque si hay un elemento diferenciador y específico que determina la actitud ética de un cineasta, éste es la mirada, es decir, la posición ideológica, moral, estética o narrativa que adopta y desde la cual cuenta la historia. La mirada es la interpretación que se hace de la realidad para que cobre sentido aquello que se cuenta. Un sentido que conlleva una actitud frente a esa realidad. Toda mirada es, por tanto, subjetiva, personal, ya que supone la 
elección de un discurso determinado frente a otros posibles, que quedan excluidos. Y es en esta subjetividad donde reside la capacidad de creación, porque la objetividad -al no tener punto de vista- no puede ser creativa y es, en sí misma, un concepto abstracto e inexistente. Este es el compromiso creativo con el que se enfrenta el cineasta: buscar una mirada, un punto de vista que dé sentido al relato cinematográfico y que sirva como reinterpretación de la propia realidad. Un compromiso en el que no caben posturas neutrales, porque toda imagen lleva implícita una ideología." (ibidem).

\section{CONCLUSIONES}

1. Ubicado en la primera generación de directores de la democracia, el cineasta Montxo Armendáriz tiene una breve pero muy consistente filmografía caracterizada por el compromiso humanista.

2. El realismo comprometido a la hora de abordar conflictos contemporáneos en la sociedad española sitúa al director en la órbita de cineastas españoles como Icíar Bollaín, Fernando León o Benito Zambrano.

3. La totalidad de los largometrajes de ficción son relatos que optan por el punto de vista personal de un narrador-personaje, lo que supone la opción por una estética cinematográfica que podemos caracterizar como humanista.

4. El estilo cinematográfico de este director posee rasgos como las elipsis, ausencia de énfasis, empatía con los personajes, trasfondo moral no moralizante o contención dramatúrgica y emocional que lo sitúan en un clasicismo compatible con un espectador adulto y participativo.

5. En este cine los espacios humanos se ubican en coordenadas espaciotemporales reconocibles, marcadamente históricas, y próximas al devenir biográfico del director.

\section{REFERENCIAS BIBLIOGRÁFICAS}

ANGULO, Jesús y otros (1998). Secretos de la elocuencia. El cine de Montxo Armendáriz. San Sebastián: Filmoteca Vasca, Fundación Caja Vital Kutxa y Festival de Málaga.

ARMENDÁRIZ, Montxo (1990). Entrevista con Carlos F. Heredero en Dirigido por, nº 184, octubre.

-(1997), "Películas de pastorcillo" en José Enrique Monterde (1997), pp. 259-262. También disponible (con el título levemente cambiado, pues aparece 'pastorcillos', en plural) en Jesús Angulo y otros (1998), pp. 326-330, y en Hilario J. Rodríguez (coord.) (2007), pp. 214-219.

-(1998a), "Entrevista", en Jesús Angulo y otros, pp. 171-297.

-(1998b), “¿Cómo mirar al otro?” en Hilario J. Rodríguez (coord.) (2007), pp. 183-194.

-(2001), "Silencio roto. Memoria de intenciones", press-book de la película, Oria Films. 


\section{6}

Compromiso y creatividad artística en el realismo de Montxo Armendáriz

-(2003), "Películas de pastorcillos 2", en Fernando Lara (coord.). Doce miradas sobre el cine europeo (El autor y su obra). Salamanca: Junta de Castilla y León, pp. 125-132.

-(2005), Entrevista de Pascual Vera en Campus Digital (Universidad de Murcia), 26 de octubre, http://www.um.es/campusdigital/entrevistas/armendariz.htm

-(2007), Entrevista personal del autor, 1 de marzo.

-(2011), "Cuando te destruyen el pasado", El País, 29-4-2011.

AUMONT, Jacques (2004). Las teorías de los cineastas. La concepción del cine de los grandes directores. Barcelona: Paidós.

BRANIGAN, Edward (1984). Point of View in the Cinema: A Theory of Narration and Subjectivity in Classical Film. La Haya: Mouton.

CONQUERO, Dolores (2002). ¡Filmando! Seis maneras de hacer cine en España. Madrid: Nuer.

MAGNY, Joël (2001). Le point de vue. París: Cahiers du Cinéma.

MARTíN GUTIÉRREZ, Gregorio (ed., 2008). Cineastas frente al espejo. Madrid: T\&B y Festival de Cine de Las Palmas.

MONTERDE, José Enrique (1997). La imagen negada: Representaciones de la clase trabajadora en el cine. Valencia: Filmoteca de la Generalitat Valenciana.

NICHOLS, Bill (1997). La representación de la realidad. Cuestiones y conceptos sobre el documental. Barcelona: Paidós.

RODRÍGUEZ, Hilario J. (coord.)(2007). Montxo Armendáriz. Itinerarios. Cáceres: Asociación Cinéfila Re Bross, Filmoteca de Extremadura, Asamblea de Extremadura, Ocho y Medio.

SÁNCHEZ NORIEGA, José Luis (2000). De la literatura al cine. Teoría y análisis de la adaptación. Barcelona: Paidós.

SANGRO, Pedro (2011). La práctica del visionado cinematográfico. Madrid: Síntesis.

\section{Breve semblanza biográfica del autor}

José Luis Sánchez Noriega es profesor de Historia del Cine en la Universidad Complutense y conferenciante en el centro de estudios para extranjeros IES-Madrid. Entre sus obras destacan Crítica de la seducción mediática (Tecnos, 2002), Diccionario temático del cine (Cátedra, 2004), De la literatura al cine (Paidós, 2000) y el manual Historia del Cine (Alianza, 2006), vigente en muchas universidades como libro de referencia. Coordina el Equipo Reseña que publica los anuarios Cine para leer y mantiene la página web homónima.

(Recibido el 07-07-2011; aceptado el 31-01-2012) 